\title{
Evaluation of corneal changes after myopic LASIK using the Pentacam ${ }^{\circledR}$
}

This article was published in the following Dove Press journal:

Clinical Ophthalmology

7 September 2013

Number of times this article has been viewed

\section{Yehia M Khairat \\ Yasser H Mohamed \\ Ismail ANO Moftah \\ Narden N Fouad}

Department of Ophthalmology, Faculty of Medicine, El-Minya

University, Egypt
Correspondence: Ismail ANO Moftah Department of Ophthalmology, Faculty of Medicine, El-Minya University, Kornish El-nile street,

El-Minya, 6I I I I, Egypt

Tel +20 I00 2554 II6

Email ismailmoftahI@yahoo.com
Background: In this study, we used a Pentacam ${ }^{\circledR}$ device to evaluate the corneal changes that occur after laser-assisted in situ keratomileusis (LASIK).

Methods: Our study included 60 eyes of 32 patients. All patients were treated for myopia and myopic astigmatism using LASIK. The eyes were examined preoperatively and 3 months postoperatively using a Pentacam to assess corneal changes with regard to curvature, elevation, and asphericity of the cornea.

Results: A statistically significant decrease in mean keratometric power of the anterior corneal surface $(P=0.001)$ compared with its pre-LASIK value was detected after 3 months, but there was no significant change in keratometric power of the posterior surface $(P=0.836)$. Asphericity (Q-value) of the anterior and posterior surfaces increased significantly after LASIK $(P=0.001)$. A significant forward bulge of the anterior corneal surface $4 \mathrm{~mm}$ and $7 \mathrm{~mm}$ from the central zone was detected 3 months post-LASIK ( $P=0.001$ for both), but there was no significant increase in posterior elevation at $4 \mathrm{~mm}$ and $7 \mathrm{~mm}$ from the center $(P=0.637$ and $P=0.26$, respectively). No cases of post-LASIK ectasia were detected. Correlation between different parameters of the corneal surface revealed an indirect relation between changes in pachymetry and anterior corneal elevation at $4 \mathrm{~mm}$ and $7 \mathrm{~mm}$ from the central zone $(\mathrm{r}=-0.27, P=0.13$, and $\mathrm{r}=-0.37$, $P=0.04$, respectively), and a direct proportion between changes in pachymetry and mean keratometric power of the anterior and posterior corneal surfaces $(\mathrm{r}=0.7, P=0.001$ and $\mathrm{r}=0.4$, $P=0.028$, respectively).

Conclusion: LASIK causes significant changes at the anterior corneal surface but the effect is subtle and insignificant at the posterior surface.

Keywords: LASIK, laser-assisted in situ keratomileusis, Pentacam ${ }^{\circledR}$, corneal elevation, corneal asphericity

\section{Introduction}

Laser-assisted in situ keratomileusis (LASIK), commonly referred to simply as laser eye surgery, is a type of refractive surgery commonly used for correction of myopia, hyperopia, and astigmatism. Laser is used to reshape the cornea in order to improve visual acuity. ${ }^{1}$ The Pentacam ${ }^{\circledR}$ (Oculus Inc, Arlington, WA, USA) is a rotating Scheimpflug camera which measures Scheimpflug images of the anterior eye segment. The Scheimpflug technique provides sharp and crisp images that include information from the anterior corneal surface to the posterior crystalline lens capsule.

With the Pentacam, topographic analysis of the front and back surfaces of the cornea is based on the true elevation measurement from one side of the cornea to the other, ie, limbus to limbus. ${ }^{2}$ 
One of the most important measurements taken at the cornea besides its shape is its true thickness, ie, the difference between the anterior and posterior elevations. Because the Pentacam provides highly accurate information about both the front and back surfaces of the cornea, it is possible to generate 25,000 data points that describe the true thickness of the cornea across its entire breadth and width. In this study, we used the Pentacam device to evaluate changes affecting the cornea after LASIK.

\section{Materials and methods}

This study included 60 eyes from 32 patients. Forty-two eyes were in female patients $(70 \%), 18$ eyes were in male patients (30\%), and mean patient age was $27.3 \pm 6.66$ (19-43) years. All patients enrolled in this prospective study had myopia with or without astigmatism and a mean spherical equivalent of $-5.07 \pm 2.1 \mathrm{D}$. All patients had refraction stability for at least 1 year. Pentacam examinations were performed preoperatively and 3 months postoperatively between December 2011 and April 2012. In general, no LASIK procedures were performed if pachymetry was less than $500 \mu \mathrm{m}$ or the residual stromal bed thickness was less than $300 \mu \mathrm{m}$.

\section{Pentacam examination}

Pentacam examination was done before and 3 months after LASIK to assess corneal thickness. Both surfaces of the cornea were examined for curvature by assessment of the radius of the horizontal $(\mathrm{Rh})$ and vertical (Rv) meridians, mean keratometric power, elevations, and asphericity (Q-value).

The anterior and posterior corneal elevation and changes were obtained at the center (eight points $4 \mathrm{~mm}$ from the center at $0^{\circ}, 45^{\circ}, 90^{\circ}, 135^{\circ}, 180^{\circ}, 225^{\circ}, 270^{\circ}$, and $315^{\circ}$ semi-meridians), and periphery (14 points $7 \mathrm{~mm}$ from the center at $15^{\circ}, 45^{\circ}, 60^{\circ}, 90^{\circ}, 120^{\circ}, 135^{\circ}, 165^{\circ}, 195^{\circ}, 225^{\circ}$, $245^{\circ}, 270^{\circ}, 295^{\circ}, 315^{\circ}$, and $345^{\circ}$ semi-meridians). In all mathematical analyses, we set $0^{\circ}$ at a point on the right and moved counterclockwise in both eyes.

\section{Surgical technique}

The laser treatments were performed under topical anesthesia using a Visx ${ }^{\mathrm{TM}}$ excimer laser (Abbott Medical Optics Inc, Abbott Park, IL, USA) after creating a corneal flap with an automated M2 microkeratome (Moria Inc, Doylestown, PA, USA) loaded with a single-use $90 \mu \mathrm{m}$ head. The optical zone used was $6.5 \mathrm{~mm}$ in diameter with a transition zone of $8.5 \mathrm{~mm}$. The target refraction for all patients was emmetropia. The postoperative evaluation was done on the first postoperative day by slit-lamp examination. The patients were examined by slit-lamp biomicroscopy, (Nidek SL 450, Nidek Co., Ltd, Aichi, Japan) manifest refraction, and uncorrected visual acuity at 1 week, 1 month, and 3 months. Preoperative and postoperative parameters as well as preoperative versus postoperative changes were analyzed using Statistical Package for the Social Sciences software (version 17, SPSS Inc, Chicago, IL, USA) and the paired two-sided $t$-test. A $P$-value $<0.05$ was considered to be statistically significant.

\section{Results}

This study included 60 eyes from 32 patients, 21 eyes of female patients (70\%), and nine eyes of male patients (30\%), and patient age ranged from 19 to 43 years. The mean age was $27.3 \pm 6.66$ years. Preoperative and postoperative data are summarized in Table 1.

Three months after LASIK, uncorrected visual acuity ranged from 0.7 to 1.0 with a mean of $0.83 \pm 0.18$, and was not significantly different from the pre-LASIK best corrected visual acuity $(P=0.254)$. A statistically significant decrease in mean keratometric power at the anterior corneal surface was detected after 3 months compared with the pre-LASIK value (38.8 \pm 2.1 , range $34.7-42.6, P=0.001)$. There was no significant change in keratometric power at the posterior surface (mean $-6.34 \pm 0.27 \mathrm{D}$, range -5.9 to $-6.8 \mathrm{D}, P=0.836$ ).

The asphericity (Q-value) of the anterior and posterior surfaces increased significantly after LASIK $(P=0.001)$.

Table I Preoperative and postoperative data

\begin{tabular}{|c|c|c|c|c|}
\hline & \multicolumn{2}{|c|}{ Preoperative data } & \multicolumn{2}{|c|}{ Postoperative data } \\
\hline & Range & Mean \pm SD & Range & Mean \pm SD \\
\hline Refraction & -2 to -8 & $-5.07 \pm 2.1$ & $\begin{array}{l}-0.25 \text { to } \\
1.00\end{array}$ & $-0.24 \pm 0.62$ \\
\hline BCVA & $0.7-1.00$ & $0.80 \pm 0.20$ & $0.7-1.00$ & $0.83 \pm 0.18$ \\
\hline Pachymetry & $500-588$ & $540 \pm 6.3$ & $407-563$ & $470.5 \pm 8.9$ \\
\hline Anterior & -0.02 to & $-0.3 \pm 0.2$ & $0.04-1.55$ & $0.7 \pm 0.3$ \\
\hline Q-value & -0.59 & & & \\
\hline Posterior & -0.50 to & $-0.02 \pm 0.16$ & -0.03 to & $0.2 \pm 0.14$ \\
\hline Q-value & 0.38 & & 0.65 & \\
\hline Anterior Km & $42 . I-46.5$ & $43.6 \pm 1.38$ & $34.7-42.6$ & $38.8 \pm 2.1$ \\
\hline Posterior Km & $\begin{array}{l}-6.1 \text { to } \\
-7.00\end{array}$ & $-6.34 \pm 0.30$ & -5.9 to -6.9 & $-6.34 \pm 0.27$ \\
\hline $\begin{array}{l}\text { Rh anterior } \\
\text { surface }\end{array}$ & $7.36-8.21$ & $7.8 \pm 0.2$ & $7.97-9.74$ & $8.7 \pm 0.4$ \\
\hline $\begin{array}{l}\text { Rv anterior } \\
\text { surface }\end{array}$ & $7.06-8.18$ & $7.6 \pm 0.3$ & $7.87-9.48$ & $8.6 \pm 0.5$ \\
\hline $\begin{array}{l}\text { Rh posterior } \\
\text { surface }\end{array}$ & $5.92-6.95$ & $6.5 \pm 0.3$ & $5.97-7.02$ & $6.5 \pm 0.25$ \\
\hline $\begin{array}{l}\text { Rv posterior } \\
\text { surface }\end{array}$ & $5.45-6.61$ & $6.1 \pm 0.3$ & $5.49-6.59$ & $6.1 \pm 0.3$ \\
\hline
\end{tabular}

Abbreviations: BCVA, best corrected visual acuity; Rh, maximum radius of curvature; Rv, minimum radius of curvature; SD, standard deviation; Km, mean keratometric power. 
The mean anterior Q-value was $-0.3 \pm 0.2$ (range -0.02 to -0.59 ), while the posterior $\mathrm{Q}$-value was $-0.2 \pm 0.16$ (range -0.05 to 0.38 ). Three months post-LASIK, the asphericity of the anterior surface changed to $0.7 \pm 0.3(0.04-1.55)$ and the posterior surface to $0.2 \pm 0.14$ ( -0.03 to 0.65 ).

Three months after LASIK, mathematical calculation of the anterior elevation at $4 \mathrm{~mm}$ from the center ranged from -3 to $50 \mu \mathrm{m}$ with a mean of $25.9 \pm 13.3 \mu \mathrm{m}$ and that at $7 \mathrm{~mm}$ from the center ranged from 72 to $244 \mu \mathrm{m}$ with a mean of $168.5 \pm 54.3 \mu \mathrm{m}$, indicating a statistically significant increase in anterior corneal elevation in comparison with pre-LASIK data $(P=0.001$ for both, Table 2$)$.

Mathematical calculation of the posterior elevation postLASIK was increased. At a $4 \mathrm{~mm}$ zone from the center it ranged from -24 to $32 \mu \mathrm{m}$ with a mean of $2 \pm 15.5 \mu \mathrm{m}$ and that at $7 \mathrm{~mm}$ from the center ranged from -176 to $108 \mu \mathrm{m}$ with a mean of $-80.4 \pm 63 \mu \mathrm{m}$ but this change was not statistically significant $(P=0.637$ and $P=0.26$, respectively, Table 3).

Three months after LASIK, the $\mathrm{Rh}$ ranged from $7.97 \mathrm{~mm}$ to $9.74 \mathrm{~mm}$ with a mean of $8.7 \pm 0.4 \mathrm{~mm}$, while that of Rv ranged from $7.87 \mathrm{~mm}$ to $9.48 \mathrm{~mm}$ with a mean of $8.6 \pm 0.5 \mathrm{~mm}$ for the anterior surface, indicating a statistically significant increase in both measurements 3 months after LASIK ( $P=0.001$ for both).

For the posterior surface, the $\mathrm{Rh}$ ranged from $5.97 \mathrm{~mm}$ to $7.02 \mathrm{~mm}$ with a mean of $6.5 \pm 0.25 \mathrm{~mm}$, while that of the Rv ranged from $5.49 \mathrm{~mm}$ to $6.59 \mathrm{~mm}$ with a mean of $6.1 \pm 0.3 \mathrm{~mm}$. This change was not statistically significant ( $P=0.695$ and $P=0.720$, respectively).

In regards to the correlation of the different corneal parameters, we found an indirect relation between changes in pachymetry and anterior corneal elevation at $4 \mathrm{~mm}$ and $7 \mathrm{~mm}$ from the central zone $(\mathrm{r}=-0.27, P=0.13$ and $\mathrm{r}=-0.37$, $P=0.04$, respectively, Figure 1), and a direct proportion between changes in pachymetry and mean keratometric power of the anterior and posterior corneal surfaces $(r=0.7$,

Table 2 Comparison of anterior elevation at $4 \mathrm{~mm}$ and $7 \mathrm{~mm}$ from the center before and 3 months after LASIK

\begin{tabular}{llll}
\hline $\begin{array}{l}\text { Anterior } \\
\text { elevation }\end{array}$ & Preoperative & $\begin{array}{l}\text { Three months } \\
\text { postoperative }\end{array}$ & P-value \\
\hline Central $\mathbf{4 ~ m m}$ & -25 to 7 & -3 to 50 & 0.001 \\
Range & $-4.4 \pm 7.5$ & $25.9 \pm 13.3$ & \\
Mean \pm SD & -108 to 14 & $72-244$ & 0.001 \\
Peripheral $\mathbf{7 ~ m m}$ & $-59.4 \pm 29.6$ & $168.5 \pm 54.3$ & \\
Range &
\end{tabular}

Abbreviations: SD, standard deviation; LASIK, laser-assisted in situ keratomileusis.
Table 3 Comparison of the posterior elevation at $4 \mathrm{~mm}$ and $7 \mathrm{~mm}$ from the center before and 3 months post-LASIK

\begin{tabular}{llll}
\hline $\begin{array}{l}\text { Posterior } \\
\text { elevation }\end{array}$ & Preoperative & $\begin{array}{l}\text { Three months } \\
\text { postoperative }\end{array}$ & P-value \\
\hline $\begin{array}{l}\text { Center } 4 \mathbf{~ m m} \\
\text { Range }\end{array}$ & -24 to 33 & -24 to 32 & 0.637 \\
$\begin{array}{l}\text { Mean } \pm \text { SD } \\
\text { Peripheral } 7 \mathbf{~ m m}\end{array}$ & $0.63 \pm 14.3$ & $2 \pm 15.5$ & \\
Range & -197 to -21 & -176 to 108 & 0.26 \\
Mean \pm SD & $-102 \pm 45.5$ & $-80.4 \pm 63$ & \\
\hline
\end{tabular}

Abbreviations: SD, standard deviation; LASIK, laser-assisted in situ keratomileusis.

$P=0.001$ and $\mathrm{r}=0.4, P=0.028$, respectively). There was no correlation between posterior corneal surface elevation (both at $4 \mathrm{~mm}$ and $7 \mathrm{~mm}$ from the center after 3 months) and residual bed thickness $(\mathrm{r}=0.005, P=0.979$ and $\mathrm{r}=0.001$, $P=0.602$, respectively, Figure 2). Further, no correlation was found between anterior and posterior elevation at $4 \mathrm{~mm}$ and $7 \mathrm{~mm}$ from the center $(\mathrm{r}=0.068, P=0722$ and $\mathrm{r}=0.054$ and $P=0.775$, respectively, Figure 3 ).

\section{Discussion}

LASIK is intended to change the shape of the anterior surface of the cornea, thus changing its refractive power. ${ }^{3}$ As long as surgery affects the anterior corneal surface and weakens the cornea, a modification in the posterior corneal surface may be expected. ${ }^{4}$ This prospective study was conducted using 60 eyes from 32 myopic patients suitable for LASIK to evaluate the effect of LASIK on the cornea. Assessment of changes at the anterior and posterior corneal surfaces before and 3 months after LASIK was done using the Pentacam. The study included patients with spherical error up to $-8 \mathrm{D}$, cylinder up to $-4 \mathrm{D}$, and central corneal thickness ranging from $500 \mu \mathrm{m}$ to $627 \mu \mathrm{m}$ with a mean of $540 \pm 6.3 \mu \mathrm{m}$.

In 2001, Seitz et al reported an increase in posterior corneal surface elevation following LASIK, ${ }^{5}$ but the pathogenesis behind this observation was poorly understood and controversial. ${ }^{6}$ In 2002, Dimitri et al found no statistically significant change in mean keratometric power at the posterior surface 3 months after LASIK, ${ }^{7}$ and this is in agreement with our study. Mean post-LASIK visual acuity was $0.83 \pm 0.18$, with no statistically significant change between this value and preoperative best corrected visual acuity. Sectorial analysis of corneal asphericity revealed significant vertical asymmetry. Specifically, the cornea tends to become steeper in the inferior area of both corneal surfaces. ${ }^{8}$

A significant change in Q-value (asphericity) for the anterior and posterior corneal surfaces was found 3 months postoperatively $(P=0.001)$. This result is in agreement 

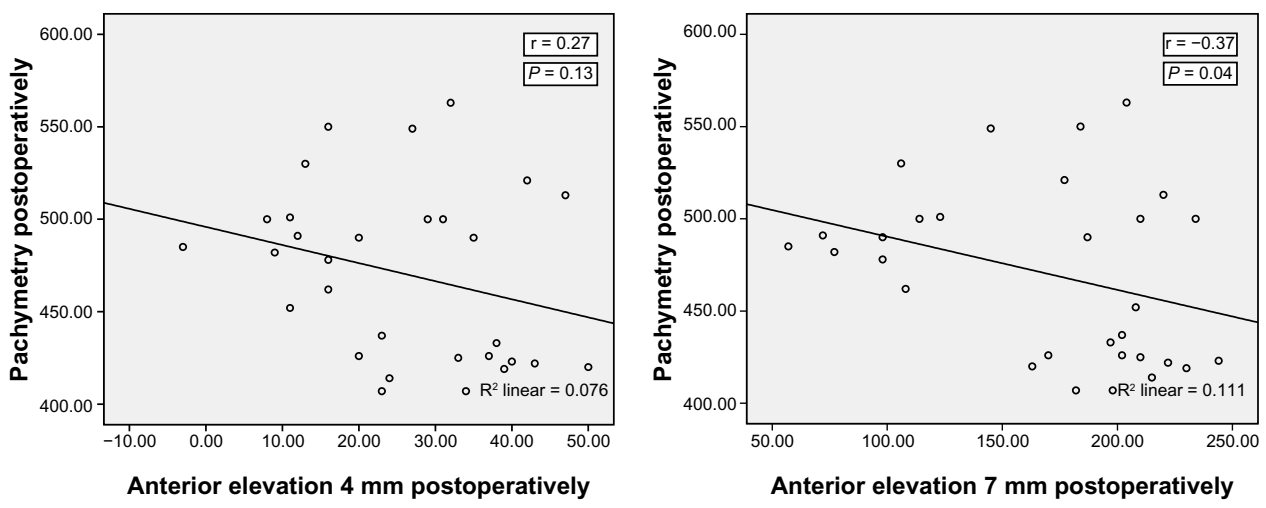

Figure I Correlation between pachymetry and anterior corneal elevation at $4 \mathrm{~mm}$ and $7 \mathrm{~mm}$ from the central corneal zone.

with that of a study by Bottos et al, who reported highly significant changes in the Q-value after LASIK. ${ }^{9}$ There was a tendency for the $\mathrm{Q}$ value to become more positive after myopic ablation. Also, the finding of asphericity at the posterior corneal surface is consistent with a report by Hou et al, who found that the Q-value showed a statistically significant positive shift. ${ }^{10}$

In 1999, Wang et al found that the posterior corneal bulge is correlated with residual corneal bed thickness, and the risk of ectasia may be increased if the residual corneal bed is thinner than $250 \mu \mathrm{m} .{ }^{11}$ In our study, the mean postoperative corneal thickness was $470 \pm 8.9 \mu \mathrm{m}$. We used a $90 \mu \mathrm{m}$ blade which created a flap $110 \mu \mathrm{m}$ in thickness, so the residual stromal bed was nearly $360 \mu \mathrm{m}$. There were no cases of ectasia.

Our study revealed a significant change in the radii of curvature ( $\mathrm{Rh}$ and $\mathrm{Rv}$ ) for the anterior corneal surface ( $P=0.001$ for both), but no significant change at the posterior corneal surface $(P=0.695$ and $P=0.720$, respectively). This is in line with a 2009 report by Pérez-Escudero et al, who demonstrated no change in the posterior radius of curvature 3 months following LASIK, but their study demonstrated

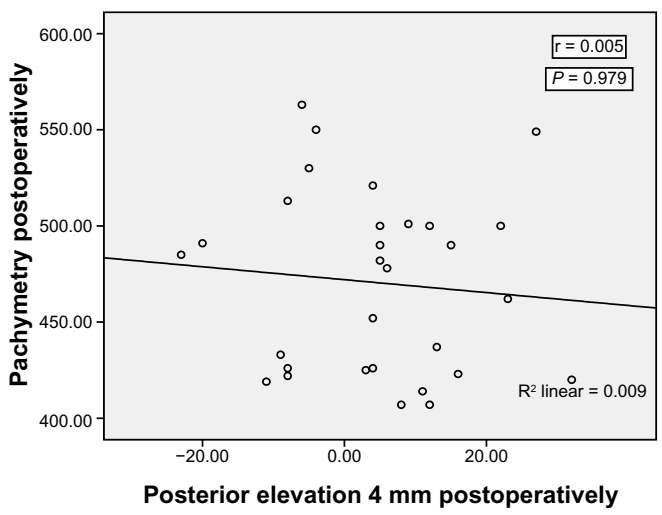

that changes in the posterior radius of curvature occurred primarily in the vertical direction (ie, Rv) and increased again. ${ }^{12}$ They suggested three possible causes for this effect. It is possible that surgery affects corneal stability more strongly in the vertical direction. This might be due to asymmetric ablation for correction of astigmatism. Even with symmetric ablation, corneal stability might be more strongly affected in the vertical direction because of the direction of the flap, which is cut in the vertical direction, leaving a superior hinge. Alternatively, meridian-independent surgery may cause a greater change in the vertical meridian if there is greater mechanical stress on the cornea in that direction. This higher mechanical stress may be caused by the eyelid, which presses on the superior part of the cornea and has been shown to modify the corneal geometry, having an impact on corneal aberrations. ${ }^{13}$ Interestingly, the intralamellar cohesive strength, studied in human eye bank corneas, has been shown to be lower in the vertical meridian than in the horizontal meridian, suggesting that even a symmetric force applied to the cornea may result in asymmetric corneal deformation. ${ }^{14}$ It is interesting to note that, in previous studies, the vertical posterior radius of curvature was found to be the least

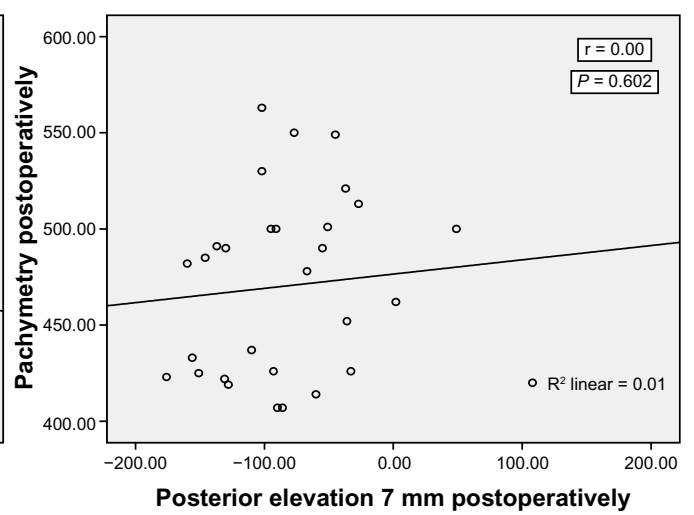

Figure 2 Correlation between pachymetry and posterior corneal elevation at $4 \mathrm{~mm}$ and $7 \mathrm{~mm}$ from the central corneal zone. 

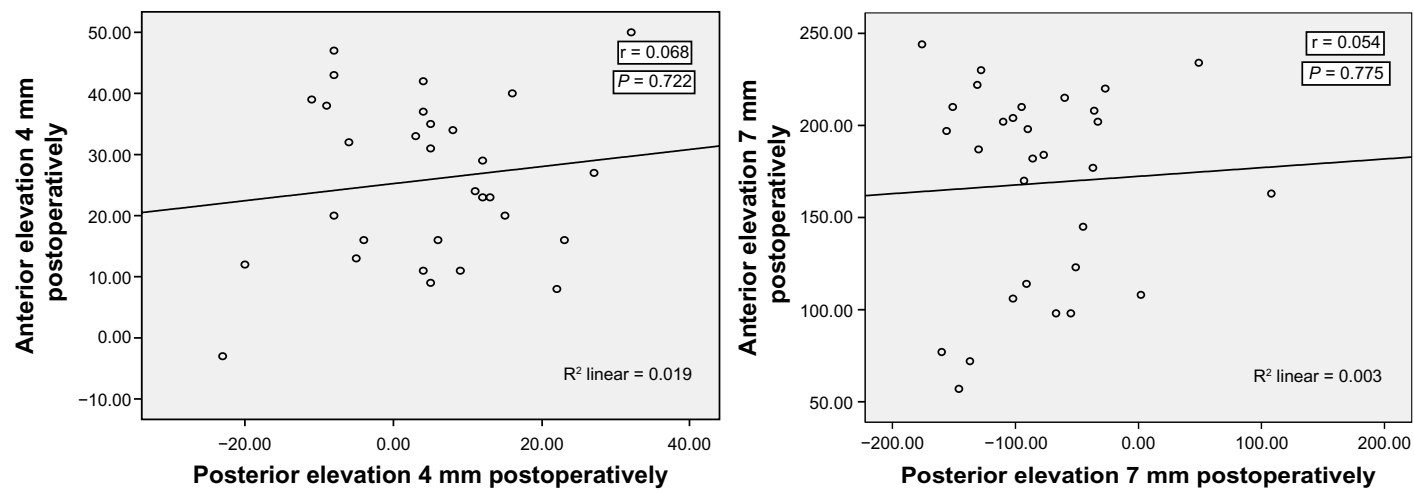

Figure 3 Correlation between anterior and posterior corneal elevation at $4 \mathrm{~mm}$ and $7 \mathrm{~mm}$ from the central corneal zone.

repeatable of the parameters measured by Pentacam in post-LASIK subjects. ${ }^{15}$

Further, mathematical calculation of the anterior corneal elevation was done preoperatively at both the paracentral rings ( $4 \mathrm{~mm}$ from the center) and peripheral rings $(7 \mathrm{~mm}$ from the center) of the central $9 \mathrm{~mm}$ zone of the cornea to obtain the change in elevation. Our results show a significant increase in anterior corneal elevation at $4 \mathrm{~mm}$ and $7 \mathrm{~mm}$ from the center 3 months after LASIK ( $P=0.001$ and $P=0.001$, respectively).

Mathematical calculation of the posterior corneal elevation was done preoperatively at both the paracentral rings $(4 \mathrm{~mm}$ from the center) and peripheral rings ( $7 \mathrm{~mm}$ from the center) of the central $9 \mathrm{~mm}$ zone of the cornea to obtain the change in elevation. We found no significant change in posterior corneal elevation at $4 \mathrm{~mm}$ and $7 \mathrm{~mm}$ from the center $(P=0.637$ and $P=0.26$, respectively) 3 months after LASIK. In 2008, Vicente et al found a statistically significant difference in posterior corneal elevation pre and post-LASIK enhancement. ${ }^{16}$ In 2001, Oshika et $\mathrm{al}^{6}$ did a study in 196 eyes from 120 subjects with myopic refractive errors in order to evaluate the forward shift of the posterior cornea after LASIK, and found that LASIK induces a forward shift of the posterior corneal surface and that eyes with thinner corneas and higher myopia are more predisposed to anterior shift of the cornea.

In 2010, Zhang and Wang compared the mean changes in posterior corneal elevation after LASIK and epi-LASIK along four optical zones (center, and $2 \mathrm{~mm}, 4 \mathrm{~mm}$, and $6 \mathrm{~mm}$ from the center) using OrbscanII, (Bausch \& Lomb Incorporated, Rochester, NY, USA). They found slight forward displacement in posterior corneal elevation at 1 month after LASIK that was statistically significant. ${ }^{17}$ In 2006, Ciolino and Belin studied posterior corneal changes after LASIK and photorefractive keratectomy with a Pentacam and found no posterior corneal changes in either group, which agrees with our results. ${ }^{18}$
Correlation between elevation of the anterior surface at $4 \mathrm{~mm}$ and $7 \mathrm{~mm}$ from the central zone and residual bed thickness revealed an indirect relation between them $(\mathrm{r}=-0.27$, $P=0.13$ and $\mathrm{r}=-0.37, P=0.14$, respectively) 3 months after LASIK. The correlation was fair for both. This result is in line with that of Miyata et al who found in their 2004 study that even if a residual corneal bed of $300 \mu \mathrm{m}$ or thicker is preserved after LASIK, anterior bulging of the cornea can occur. ${ }^{19}$ While elevation of the posterior corneal surface at $4 \mathrm{~mm}$ and $7 \mathrm{~mm}$ from central zone was not correlated with residual bed thickness 3 months post-LASIK ( $\mathrm{r}=0.005$, $P=0.979$ and $\mathrm{r}=0.00, P=0.602$, respectively). In 2001, Hernandez et al suggested that changes in the posterior corneal surface after refractive surgery may not be related to the variability of refractive results or the depth of ablation. ${ }^{20}$ Correlation between anterior and posterior corneal surface elevation 3 months post-LASIK revealed a fair, direct correlation $4 \mathrm{~mm}$ from the center zone and a very weak, indirect correlation at $7 \mathrm{~mm}$ from the center zone.

\section{Disclosure}

The authors report no conflicts of interest in this work.

\section{References}

1. Groden LR, Shah VC. Safe LASIK: a primer. Int Ophthalmol Clin. 2006;46:83-90.

2. Gherghel D, Hosking SL, Mantry S, Banerjee S, Naroo SA, Shah S. Corneal pachymetry in normal and keratoconic eyes: Orbscan II versus ultrasound. J Cataract Refract Surg. 2004;30:1272-1277.

3. Pallikaris IG, Papatzanaki ME, Stathi EZ, Frenschock O, Georgiadis A. Laser in situ keratomileusis. Lasers Surg Med. 1990;10:463-468.

4. Dupps WJ Jr. Biomechanical modeling of corneal ectasia. J Refract Surg. 2005;21:186-190.

5. Seitz B, Torres F, Langenbucher A, Behrens A, Suárez E. Posterior corneal curvature changes after myopic laser in situ keratomileusis. J Ophthalmol. 2001;108:666-672.

6. Baek T, Lee K, Kagaya F, Tomidokoro A, Amano S, Oshika T. Factors affecting the forward shift of posterior corneal surface after laser in situ keratomileusis. Acta Ophthalmol. 2001;108:317-320. 
7. Azar DT, Koch DD. LASIK fundamentals, surgical techniques and complications. Taylor, chapter. 2002;11:163-170.

8. Piñero DP, Alió JL, Alesón A, Escaf Vergara M, Miranda M. Corneal volume, pachymetry, and correlation of anterior and posterior corneal shape in subclinical and different stages of clinical keratoconus. $J$ Cataract Refract Surg. 2010;36:814-825.

9. Bottos KM, Leite MT, Aventura-Isidro M, et al. Corneal asphericity and spherical aberration after refractive surgery. $J$ Cataract Refract Surg. 2011;37:1109-1115.

10. Hou J, Wang Y, Li J, Yang XY, Zhang L. [Change of asphericity of posterior corneal surface after refractive surgery.] Zhonghua Yan Ke Za Zhi. 2011;47:223-227. Chinese.

11. Wang Z, Chen J, Yang B. Posterior corneal surface topographic changes after laser in situ keratomileusis are related to residual corneal bed thickness. Ophthalmology. 1999;106:406-409.

12. Pérez-Escudero A, Dorronsoro C, Sawides L, Remón L, MerayoLloves J, Marcos S. Minor influence of myopic laser in situ keratomileusis on the posterior corneal surface. Invest Ophthalmol Vis Sci. 2009;50:4146-4154.

13. Buehren T, Collins MJ, Carney L. Corneal aberrations and reading. Optom Vis Sci. 2003;80:159-166.
14. Smolek MK. Interlamellar cohesive strength in the vertical meridian of human eye bank corneas. Ophthalmol Vis Sci. 1993;34:2962-2969.

15. Jain R, Dilraj G, Grewal SP. Repeatability of corneal parameters with Pentacam after laser in situ keratomileusis. Indian J Ophthalmol. 2007;55:341-347.

16. Vicente D, Clinch TW, Kang PC. Changes in anterior corneal elevation after laser in situ keratomileusis enhancement. $J$ Cataract Refract Surg. 2008;34:785-788.

17. Zhang L, Wang Y. The shape of the posterior corneal surface in normal, post LASIK and post epi-LASIK eyes. Invest Ophthalmal Vis.Sci. 2010;51(7):3468-3475.

18. Ciolino JB, Belin MW. Changes in the posterior cornea after laser in situ keratomileusis and photorefractive keratectomy. $J$ Cataract Refract Surg. 2006;32:1426-1431.

19. Miyata K, Tokunaga T, Nakahara M, et al. Residual bed thickness and corneal forward shift after laser in situ keratomileusis. J Cataract Refract Surg. 2004;30:1067-1072.

20. Hernández-Quintela E, Samapunphong S, Khan BF, et al. Posterior corneal surface changes after refractive surgery. Ophthalmology. 2001;108:1415-1422.
Clinical Ophthalmology

\section{Publish your work in this journal}

Clinical Ophthalmology is an international, peer-reviewed journal covering all subspecialties within ophthalmology. Key topics include: Optometry; Visual science; Pharmacology and drug therapy in eye diseases; Basic Sciences; Primary and Secondary eye care; Patient Safety and Quality of Care Improvements. This journal is indexed on Submit your manuscript here: http://www.dovepress.com/clinical-ophthalmology-journal

\section{Dovepress}

PubMed Central and CAS, and is the official journal of The Society of Clinical Ophthalmology (SCO). The manuscript management system is completely online and includes a very quick and fair peer-review system, which is all easy to use. Visit http://www.dovepress.com/ testimonials.php to read real quotes from published authors. 